\title{
Prospects for the development of effective pharmacotherapy targeted at the skeletal muscles in chronic obstructive pulmonary disease: a translational review
}

\author{
Michael C Steiner, ${ }^{1}$ Ronenn Roubenoff, ${ }^{2}$ Ruth Tal-Singer, ${ }^{3}$ Michael I Polkey ${ }^{4}$
}

${ }^{1}$ Institute for Lung Health, Department of Respiratory Medicine, University Hospitals of Leicester NHS Trust, Glenfield Hospital, Leicester, UK ${ }^{2}$ Musculoskeletal Translational Medicine, Novartis Institutes for Biomedical Research,

Cambridge, Massachusetts, USA

${ }^{3}$ GlaxoSmithKline, Respiratory Therapy Area Unit, King of Prussia, Pennsylvania, USA ${ }^{4} \mathrm{NIHR}$ Respiratory Biomedical Unit at the Royal Brompton Hospital and National Heart \& Lung Institute, London, UK

\section{Correspondence to}

Dr Michael C Steiner, Institute for Lung Health, Department of Respiratory Medicine, University Hospitals of Leicester NHS Trust, Glenfield Hospital, Groby Road, Leicester LE3 9QP, UK; michael.steiner@uhl-tr.nhs.uk

Received 15 February 2012 Accepted 9 April 2012

\section{ABSTRACT}

Skeletal muscle dysfunction is a prevalent and clinically important systemic manifestation of chronic obstructive pulmonary disease (COPD) that predicts morbidity and mortality. Skeletal muscle retains its plasticity in response to anabolic stimuli such as exercise in COPD and is therefore a promising target for novel pharmacological therapies aimed at reducing disability and healthcare utilisation and improving mortality. In this article, we outline the steps the academic and pharmaceutical communities need to undertake for such therapeutic advances to be realised.

\section{INTRODUCTION}

Despite the increasing health burden imposed by chronic obstructive pulmonary disease (COPD) in the developed and developing world, there have been few major advances in pharmacotherapy addressing the primary pulmonary pathophysiology underpinning the disease. Currently available drug treatments may reduce exacerbation frequency and improve symptoms but significant effects on mortality and long-term decline in lung function have been difficult to demonstrate even in large clinical trials. ${ }^{12}$ Thus, even though active case finding by spirometry is recommended (at least in the UK) and is probably beneficial for symptom and exacerbation management, there is only minimal evidence that pharmacological intervention at any severity of airflow obstruction improves long-term mortality and lung health compared with smoking cessation strategies or, if appropriate, environmental pollution prevention programmes. Equally, many patients present to health services with advanced irreversible lung damage, but lung regenerative therapy remains a distant prospect that will require considerable time and investment to be realised.

Skeletal muscle dysfunction is a frequent and clinically relevant systemic manifestation of COPD that predicts morbidity and mortality independently from the severity of lung function impairment judged by forced expiratory volume in $1 \mathrm{~s}$ $\left(\mathrm{FEV}_{1}\right.$ ) (figure 1). ${ }^{3}{ }^{4}$ The skeletal muscles therefore represent a viable target for drug development with the plausible prospect of reducing disability and healthcare utilization, and improving mortality in patients in whom lung damage is irreversible. Proof of concept for this approach comes from the unequivocal benefits of exercise training in the context of pulmonary rehabilitation (PR), ${ }^{5}{ }_{\text {which }}$ demonstrates that in patients with COPD, as in healthy older people, skeletal muscle retains its plasticity in response to anabolic therapy such as exercise. ${ }^{7-11}$

In this translational review we outline the steps the academic and pharmaceutical communities need to undertake together to develop, test and deliver drugs that improve clinical outcomes by modifying skeletal muscle function. These include:

- developing a greater understanding of the natural history and pathophysiology of skeletal muscle dysfunction in COPD;

- developing minimally invasive and cost-effective diagnostics and biomarkers for identifying clinically significant muscle disease and predicting the clinical response;

- identifying specific therapeutic targets for drug development;

- establishing a regulatory environment where efficacy in the absence of improvement in lung function is recognised.

In the context of the established efficacy of exercise training, it is likely that such therapy will be combined with rehabilitation programmes but may also be targeted at individuals or clinical situations (eg, acute exacerbations) in which voluntary exercise training is impractical. The authors, with their colleagues in the UK Medical Research Council (MRC) and Association of the British Pharmaceutical Industry (ABPI) funded collaboration (COPD MAP), have begun this process.

\section{PATHOPHYSIOLOGY AND NATURAL HISTORY OF SKELETAL MUSCLE DISEASE}

The locomotor muscles in patients with COPD tend to be weaker and smaller than age-matched controls. ${ }^{12-14}$ At biopsy, a shift towards more type II and fewer type I fibres is observed, with reduced expression of oxidative enzymes. ${ }^{15-17}$ Other observed phenomena are reduced fibre crosssectional area (CSA) and capillarity. ${ }^{15} 18$ The functional consequences of these observations are an early switch to anaerobic metabolism and greater adenine nucleotide loss during exercise, which in turn leads to premature muscle fatigue, increased load to ventilation and a reduction in exercise capacity. ${ }^{19-21}$ COPD patients with skeletal muscle dysfunction demonstrate reduced contractile endurance and a tendency to exhibit low-frequency quadriceps fatigue after an exercise task. ${ }^{22} 23$ This may act as a locus of exercise limitation, 


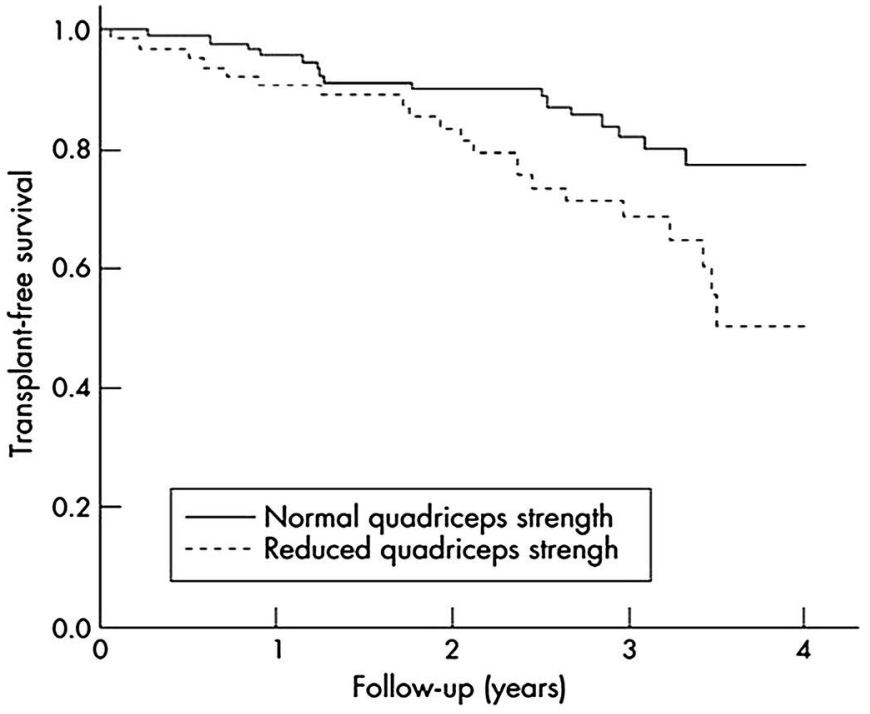

Figure 1 The impact of quadriceps muscle strength on survival in chronic obstructive pulmonary disease. Transplant-free survival for patients with normal and reduced quadriceps strength, as defined by a quadriceps maximal voluntary contraction greater or less than $120 \%$ of body mass index. The curves are significantly different, $\mathrm{p}=0.017$. (Reproduced with permission from Swallow et $\mathrm{al}^{3}$.)

demonstrated in classic series of studies showing that patients who develop quadriceps fatigue were less able to profit from a bronchodilator intervention as judged using an exercise test. ${ }^{24} 25$ Conversely exercise training is able to reduce the likelihood of fatigue developing during an exercise task. ${ }^{26}$ Both of these observations support the case for the quadriceps being a source of symptoms in COPD. Based on biopsy studies, other lower limb muscles may also contribute although, there is a paucity of data in this area. ${ }^{27}$

A full discussion of the aetiology of skeletal muscle dysfunction is beyond the scope of this review but a number of factors have been purported as making a contribution, including exaggerated systemic inflammation, malnutrition, hypoxia and drug therapy such as systemic corticosteroids. ${ }^{28} \mathrm{~A}$ consistent feature, however, is the anatomic predilection for skeletal muscle abnormalities to affect the locomotor muscles with relative sparing of the upper limb or respiratory muscles. This suggests that the reduction in habitual physical activity and fitness that usually accompanies the disease (even at its earlier stages) is a key aetiological factor. The improvements in fitness and activity seen after PR are accompanied by adaptations, at least partially, in muscle architecture and composition, ${ }^{729}$ which has implications for drug development and the clinical setting of drug administration.

Surprisingly little is known about the natural history of skeletal muscle dysfunction in COPD and a principle objective of ongoing research will be to capture this detail and identify populations of patients who are at risk. Few longitudinal data are available, although in a single centre study, 64 patients were studied 1 year apart and exhibited a $4 \%$ fall in quadriceps strength. ${ }^{30}$ Longitudinal changes in muscle function in COPD need to be interpreted in the context of sarcopenia (age-related loss of muscle mass and function), and it remains uncertain whether progressive loss of muscle function accelerates in some patients linearly or in a stepwise fashion in association with variations in the disease such as exacerbations. For several reasons an alternative paradigm is gaining ground, in which physical inactivity and skeletal muscle dysfunction represent cophenomena with smoking-related decline in lung function (figure 2). First, at a muscle biopsy level, evidence of oxidative stress may be found in smokers with normal spirometry ${ }^{31} 32$; moreover adults with normal spirometry of a comparable age to patients with COPD with a past or present history of smoking are weaker than never smokers, ${ }^{14}$ and during an endurance task smokers with normal spirometry are more fatigable than never smokers. ${ }^{33}$ Second, muscle weakness is not exclusively associated with wider loss of tissue mass or the cachexia syndrome, suggesting that it is not inevitably the direct consequence of the underlying lung disease. ${ }^{30}{ }^{34}$ Third, recent evidence has suggested that reduced muscle function, muscle mass and physical activity are prevalent even in milder disease. ${ }^{14} 3536$ Consistent with this, leg discomfort is cited as a reason for exercise cessation in a proportion of patients with Global Initiative for Obstructive Lung Disease (GOLD) stage I disease. ${ }^{37}$ Moreover, data from a longitudinal cohort of older people suggested that muscle mass in those with obstructive lung disease was comparable at baseline to unobstructed smokers and trajectories of reductions in muscle mass over time did not differ between the groups, raising the possibility of an interaction early in life between smoking, lung function impairment and muscle dysfunction. ${ }^{38}$

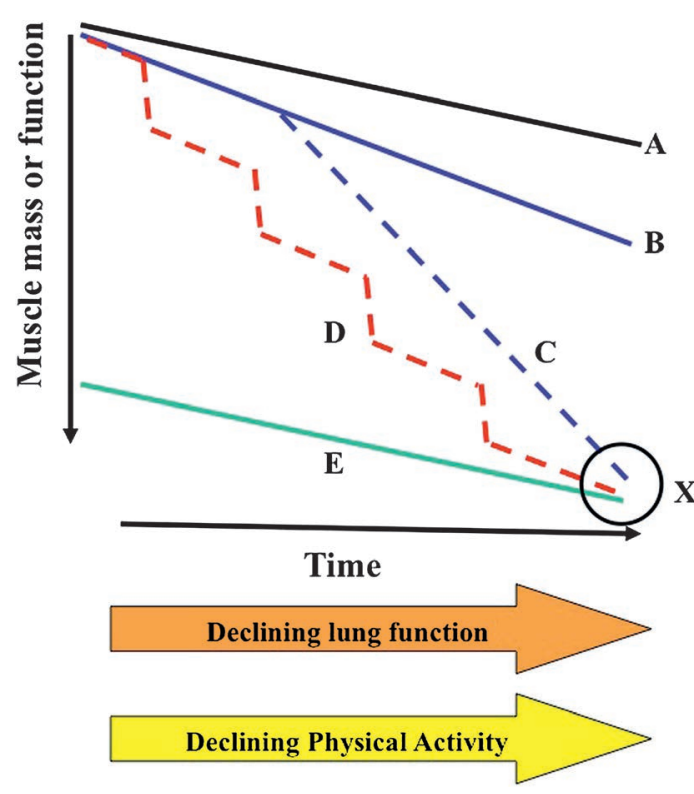

Figure 2 Possible natural histories of skeletal muscle wasting in chronic obstructive pulmonary disease. Decline in skeletal muscle function in COPD will occur on a background or age-related sarcopenia (line A) and coincident with declining lung function and physical activity. In some patients this may simply occur at a faster rate because of lower habitual physical activity (line B). A proportion of these patients may at some point in their disease develop a 'cachexia syndrome' associated with a systemic inflammatory response leading to a rapid loss of function and a poor prognosis (line C). In some patients, muscle wasting may be 'events driven', where immobilisation (and potentially other factors such as inflammation and hypoxia) during acute exacerbations of COPD lead to rapid loss of muscle mass from which the patient does not adequately recover (line D). In others, however, low muscle mass is a feature of natural body habitus and is not associated with a progressive wasting process (line $\mathrm{E}$ ). A single measurement of muscle mass at point $X$ will not distinguish these latter phenotypes, highlighting the importance of more sophisticated diagnostics and biomarkers. 
As with other causes of immobility in older people, acute exacerbation of COPD (AECOPD) is associated with loss of quadriceps strength, ${ }^{39}$ and this is a time when a drug which improved muscle function might usefully be given (see below). In addition to immobility, ${ }^{40}$ other candidate aetiological factors associated with AECOPD are inflammation and sepsis, and the use of steroids, although interestingly evidence of inflammation in muscle biopsies taken at the time of acute exacerbation has not been established. ${ }^{41}$

In any event it is now generally accepted that skeletal muscle weakness is associated with patient and payer relevant outcomes such as healthcare utilisation or death, ${ }^{3} 42$ highlighting the importance of gathering greater knowledge on the natural history and pathophysiology of this clinical syndrome.

\section{DIAGNOSTICS/BIOMARKERS FOR SKELETAL MUSCLE DISEASE}

Current methods of identifying significant muscle disease involve single measurements of muscle mass or function, which may be able to identify in an individual patient whether these indices are lower than expected for a healthy population. ${ }^{43-45}$ However, the wide variation of these characteristics in older people means that this may not on its own amount to the identification of a pathological syndrome that has adverse health consequences (see figure 2).

Detecting a subgroup of patients with clinically relevant skeletal muscle dysfunction remains problematic for academia and for the pharmaceutical industry, especially if emerging products either have unwanted side effects or are costly. An ideal biomarker or diagnostic test should be cheap, easy and universally available with robust, well validated normal values. When a targeted drug treatment addressing a specific aspect of skeletal muscle dysfunction is proposed (eg, muscle atrophy or muscle fibre shift), a range of biomarkers predicting the clinical response may be required to facilitate the stratification and/or personalisation of therapy.

Broadly two types of biomarker may be useful for muscle dysfunction; those which examine a characteristic of the muscle itself and those which capture a clinical parameter strongly related to muscle dysfunction, for example exercise performance. Considering muscle-specific markers, an obvious choice would be strength or mass since these measures relate to clinical outcomes. Objective testing of muscle strength has not become widespread outside the setting of PR programmes and the conduct of these measurements remains poorly standardised. Measuring maximal voluntary contraction force has the advantage of availability of normal values based on large age appropriate cohorts. ${ }^{14}$ Alternative measures require specialist equipment but single or repetitive magnetic nerve stimulation techniques may be useful to detect exercise-induced fatigue. ${ }^{22} 46$ Since fatiguability can be reduced by rehabilitation, conceptually this could be used to provide proof of concept for a drug with similar properties. Stimulation techniques also overcome any concerns regarding the magnitude of voluntary activation of the quadriceps, although the available data do not support this as a major problem in COPD. ${ }^{47}$ Imaging strategies may be better in this regard and are especially suitable for drug studies since the images can be read by a blinded central laboratory. The best data presently relates to CT mid-thigh cross-sectional area. ${ }^{4}{ }^{12}$ While the required radiation dose of the single CT cut is modest, in many countries getting access to CT imaging may be difficult; similar considerations apply to MRI scanning, although this is undoubtedly a feasible way of measuring quadriceps bulk. ${ }^{48}$ Ultrasound is a promising new modality, which is inexpensive and radiation free; however it only effectively images the superficial rectus femoris. Even so, preliminary observations confirm a good relationship between rectus femoris CSA and strength and CT mid-thigh CSA, although the sensitivity of an assessment of a relatively small component of the quadriceps muscle to intervention remains to be determined. ${ }^{13}$ Dual-energy X-ray absorptiometry (DEXA) scanning has been widely used in the sarcopenia field. ${ }^{49}{ }^{50}$ It has the advantage of being widely available, involves trivial radiation exposure and importantly allows assessment of both regional and total body muscle mass as well as bone mineral mass. However, cost and accessibility are also an issue with DEXA, which may prove a useful diagnostic tool but less practical as a biomarker to monitor the treatment response. A further solution would be to identify a circulating marker of muscle dysfunction or damage in the same way that troponin is a marker of acute cardiac injury. Circulating microRNA (miRNA) can be measured in other conditions ${ }^{51}$ and since quadriceps levels of some miRNAs are altered in COPD ${ }^{52}$ and relate to phenotype, this may prove a fruitful approach in COPD.

Exercise outcomes may become highly relevant to the delivery of drugs which alleviate skeletal muscle dysfunction in COPD, although clearly other factors including pulmonary mechanics may limit exercise capacity. The 6 min walk distance has been widely used in pulmonary medicine and (see below) is the subject of active regulatory discussion. However, there may be value in evaluating tests used in the assessment of sarcopenia and frailty in older people. Examples include the timed up and go test, ${ }^{53}$ short physical performance battery (or $4 \mathrm{~m}$ gait speed $)^{54} 55$ and tests of balance. ${ }^{56}$

\section{POTENTIAL THERAPEUTIC TARGETS}

To date, therapeutic approaches to reverse muscle wasting by increasing muscle mass have largely fallen into two broad categories-directly anabolic stimuli, and anti-catabolic interventions. The two are not mutually exclusive, but most molecular targets identified so far in myocytes appear to fall into one or the other category. For example, androgen therapy (testosterone and its analogues), growth hormone, and insulin-like growth factor I are primarily anabolic signals to muscle that increase protein synthesis directly. However, antibodies to interleukin 6, tumour necrosis factor $\alpha$, or myostatin all function to inhibit catabolic signals to muscle. An alternative approach has been to try and improve muscle function without much or any effect on muscle mass, as is the case with calcium secretagogues such as those being developed by cytokinetics, or possibly by the use of calcium sensitisers which have recently been shown to have a measurable effect on the human diaphragm. ${ }^{57}$

The first generation of anabolic treatments - testosterone and growth hormone-have undergone limited testing in COPD and although short-term improvements in muscle strength and mass have been observed in some studies, concerns about long-term efficacy and adverse effects have limited their widespread introduction into routine clinical practice. ${ }^{58-60}$ There is also potential theoretical concern that increasing muscle mass outside the locomotor muscles could actually, by increasing body weight, have negative effects on exercise capacity, and this will need careful attention in clinical trials. Newer selective androgen receptor modulators are in development now that are non-steroidal in structure, and are thought to be safer. ${ }^{61}$ The lead drug candidate in this class, Ostarine (GTx, Nashville, Tennessee, USA), is now in phase III studies for cancer cachexia (NCT01355484).

Inhibition of myostatin, a natural inhibitor of muscle growth, is a promising anabolic mechanism of action that is still poorly 
understood. Myostatin is of interest since intramuscular levels are elevated in patients with COPD who are disabled ${ }^{62}$ and have been reported to fall with exercise training. ${ }^{29} 63$ A phase II study testing the first molecule, stamulumab (MYO-029; Pfizer, Inc., New York, NY, USA) did not demonstrate efficacy in muscular dystrophy, ${ }^{64}$ but no data exist in the public domain concerning its effect on non-dystrophic muscle. A more recent approach taken by Acceleron Pharmaceuticals (Cambridge, MA, USA) was to target an important myostatin receptor, the activin receptor (ActRII), using an Fc fusion protein approach. ${ }^{65}$ The range of potential pathways is of course enormous and continually expanding. For a more detailed review the reader is referred to Glass. ${ }^{66}$

A unique feature of muscle atrophy in COPD is that, in contrast to observations in other settings such as age-related sarcopenia, the proportion of type I rather than type II muscle fibres is reduced. ${ }^{67}$ This suggests that therapies directed at generating type I fibres, such as those that affect the transcriptional coactivator PGC-1 $\alpha$ (peroxisome proliferator-activated receptor $\gamma$ coactivator $1 \alpha$ ), may have a role in treating COPD muscle atrophy. ${ }^{68}$ However, such approaches have not yet reached clinical testing. We note that while fibre atrophy often is reported in patients with COPD, it need not accompany type II fibre shift. Indeed the best evidence for this is that in nonlocomotor muscles, such as the diaphragm, type I fibre predominance can be observed with fibre atrophy. ${ }^{69}$

\section{CLINICAL SETTINGS (EG, EXERCISE TRAINING OR AECOPD)}

An important consideration in the development of new drugs targeting the skeletal muscles in COPD will be the clinical setting in which such therapy would be delivered. The background to these considerations is the established efficacy of exercise training on skeletal muscle and whole body exercise performance and the wider health benefits that accrue from the provision of exercise therapy in the context of clinical PR programmes.

The effects of exercise and physical activity in older people are wide ranging and include both physiological adaptation at a muscle level together with wider metabolic, psychological and behavioural benefits. There is now robust evidence that this situation also applies to exercise training in COPD, ${ }^{7} 117071$ contrary to traditional concerns that patients with significant ventilatory constraints to exercise would be unable to exercise at sufficient intensities to bring about these adaptations. However, rehabilitation practitioners would also recognise the importance of improvements in mood, self-efficacy and capacity utilisation that exercise training bequeaths. Longer-term behaviour change to a more physically active lifestyle may have other benefits, such as reductions in obesity and cardiovascular risk, although evidence which has assessed the feasibility of behaviour change, as manifested by physical activity, is conflicting. ${ }^{72-75}$ It is conceivable that a muscle anabolic drug could initiate or enhance an endurance or resistance training adaptation, but it is improbable that these wider benefits could be delivered solely by a drug acting on a single regulatory pathway. However, it is reasonable to speculate that synergy between a drug and an exercise programme could be used to maximise the effects of home-based training, or reduce the need for expensive gym-based treatment, or maintain the benefit of a rehabilitation programme after it ends. For these reasons it is likely that drugs targeting skeletal muscle function or the exercise response will be combined with exercise therapy or would target patients or situations where exercise training is impractical or undesirable. The expectation that coprescription of exercise and drug therapy will be needed brings a health policy/commissioning dimension to drug development. Despite the unequivocal benefits of exercise training in the context of $\mathrm{PR}$, the provision of the latter is extremely variable even in the developed world. For example, data from the 2008 UK national COPD audit has indicated that only $58 \%$ of acute care providers surveyed could provide PR for all eligible patients, with $10 \%$ having no access at all. ${ }^{76}$ Addressing this variation in the provision of evidence-based care should be a priority for commissioners but will clearly also become an issue for the pharmaceutical industry if candidate molecules that work synergistically with exercise come to market.

\section{Drug therapy combined with exercise training}

There have been a number of studies exploring the impact of nutritional or pharmacological therapies in combination with exercise training. These include therapies aimed at improving muscle strength and mass such as anabolic steroids ${ }^{77} 78$ or testosterone, ${ }^{5960}$ and those aimed at improving aerobic function such as carbohydrate supplementation, ${ }^{79}$ creatine $^{80} 81$ or carnitine. ${ }^{82}$ There has been only limited study of the interaction of conventional bronchodilator therapy with exercise training, but these data suggest that attention to optimising lung function may facilitate higher intensity training. ${ }^{83}$ The purpose of this review is not to describe these trials in detail but articulate broad principles that in our view should guide drug development in this setting. Many studies of the augmentation of exercise training have shown performance benefits over and above those of training alone but few have reported longer-term preservation of these performance benefits or translation into clinically meaningful or patient-centred outcomes such as health status, habitual physical activity or healthcare utilisation. This is crucial because exercise training programmes are usually of finite length and the longer-term benefits will rely on patients becoming and staying more physically active. Adjunctive therapies may also need to be sustained in the longer term in association with regular physical activity for them to deliver additional benefits and so the associated cost and safety of such therapy would need to be considered with this in mind (figure 3). Many of the therapeutic technologies employed in these studies have been adopted from the field of performance enhancement in sports and exercise. However, these interventions may deliver only small performance advantages over exercise alone, which may be perceived as worthwhile in elite sports but are too small to be detectable or beneficial in clinical settings.

Exercise training can be performed in a variety of modes dependent on the domain of performance required. Training adaptations are generally specific to the mode of training employed; for example, resistance training will bring about improvements in muscle strength and mass whereas aerobic training will result in increases in oxidative capacity and muscle endurance. Adjunctive drug therapy will need to be considered in the same light and combined with the most appropriate mode of training. For example, anabolic therapies such as testosterone or anabolic steroids would logically be combined with resistance training. An important consideration therefore will be a baseline assessment of specific performance deficits and targeting performance enhancing therapy to these specific needs. This approach is in its infancy in rehabilitation practice and may need development alongside the evaluation of new drugs.

\section{Pharmacotherapy in situations when exercise training is impractical or undesirable}

While exercise training is a desirable and effective intervention in COPD there are circumstances in which this is challenging to deliver to individual patients. Novel exercise training strategies 


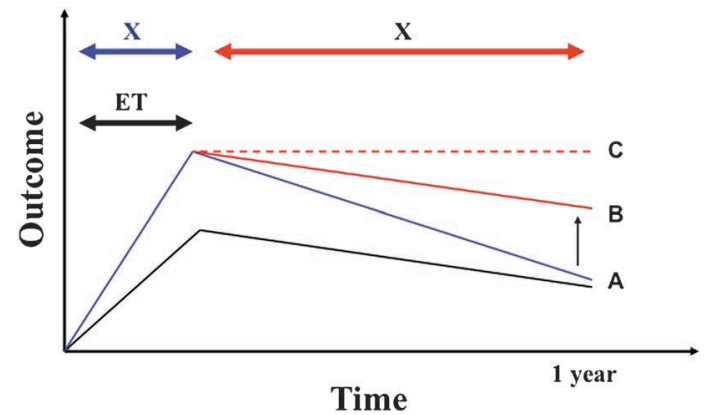

Figure 3 The enhancement of exercise training (ET) with adjunctive therapies. A schematic diagram describing theoretical effects of an adjunctive therapy (' $X$ ') delivered during ET in chronic obstructive pulmonary disease. Once ET finishes, the benefits diminish with time but are sustained above pre-training baseline at 1 year. If $X$ is discontinued when ET finishes any enhancement of outcome may diminish with time (A). If therapy $X$ is maintained, it may be possible to maintain (B) or increase $(C)$ the enhanced outcome. This will be more likely if the patient is adherent to post-training exercise maintenance. The continuation of $X$ has implications for health costs and risks of adverse toxicity.

have been proposed for patients with particularly severe lung function impairment to overcome concerns that these individuals may be unable to participate in conventional exercise training because of severe exercise related ventilatory limitation. These include high-intensity interval training, ${ }^{84} 85$ when short bursts of high-intensity exercise are interrupted by periods of rest and involuntary training strategies such as neuromuscular electrical stimulation, ${ }^{86} 87$ the adjunctive use of non-invasive ventilation $^{88}$ or low-density gas mixtures. ${ }^{89}$

Muscle anabolic drugs might have a role in initiating skeletal muscle physiological adaptation in severely impaired patients who would struggle to participate in conventional exercise training either alone or in conjunction with such novel training approaches. However, studies examining these approaches have not demonstrated superiority over conventional training methods in severely impaired patients and evidence that this population will not respond to conventional training is lacking. ${ }^{8490}$ Identifying demographical or disease characteristics that predict 'non-response' to PR has proved elusive and it may be difficult to draw broad conclusions about the target population that would be suitable for this approach.

A common problem encountered by rehabilitation teams is the patient who struggles to attend and adhere to rehabilitation classes because of disruptive acute exacerbations that result in unpredictable short term immobilisation or hospitalisation. These episodes themselves are probably key drivers of progressive deconditioning and skeletal muscle dysfunction. There is evidence that muscle mass may fall significantly in only a few days during hospitalisation for exacerbation ${ }^{39}$ and that recovery of pre-exacerbation physical activity and performance may take several weeks in some individuals. ${ }^{40}$ Studies of muscle protein synthesis following amino acid feeding in older people suggests that this response is blunted, a phenomenon that has been termed 'anabolic resistance'. 91

Exacerbations are associated with extended periods during which patients are inflamed, inactive ${ }^{40}$ (particularly if hospitalised) and may be treated with therapy such as high-dose corticosteroids that have a potentially negative effect on muscle mass. Anabolic therapies targeting these episodes of acute 'muscle risk' have the potential to preserve skeletal muscle function, accelerate the recovery of functional performance following the event and slow the longer-term progression of muscle dysfunction. The advantages of this approach would be limitation of healthcare costs and reduced risk of adverse effects because treatment would be restricted to the acute illness, in addition potentially to reducing the risk of readmission. Several data suggest that an anabolic stimulus, at least in the form of rehabilitation, is beneficial as is the case for PR given soon after $\mathrm{AECOPD}^{9}$ or during admission. ${ }^{63}$

\section{REGULATORY ISSUES}

It is currently accepted by regulatory agencies that COPD may be associated with important systemic consequences including decreased functional capacity manifested by exercise limitation. Although this reduced functional capacity has been clearly associated with poor outcomes such as mortality and hospitalizations, ${ }^{92-96}$ there is no accepted drug development tool (DDT) to select subsets of patients with muscle dysfunction (stratification) or assess muscle dysfunction or activity limitation as outcomes in COPD clinical trials. As a result, 'all-comer' COPD intervention studies with novel drug candidates assessing outcomes such as mortality, or exacerbations of COPD have required very large sample sizes or prolonged study durations. From an industry perspective, the existing acceptable DDTs (change in $\mathrm{FEV}_{1}$, exacerbation frequency, and mortality) are unlikely to capture benefits from novel therapies, which might reduce disability, improve patient quality of life and reduce healthcare utilisation by addressing skeletal muscle dysfunction. The need for such DDTs is highlighted by the observation that, were it a drug, PR might not have sufficient evidence to attain regulatory approval based on existing criteria. An important limitation to primary clinical trials of combined exercise and pharmacological therapy is the reluctance of regulators to approve a drug based on a combination with exercise unless the exercise regimen itself becomes part of the label. This is a major practical constraint on sponsors, because there is an almost infinite variety of exercise regimens, and they cannot all be studied during drug development. This leads to the situation that most drugs must be approved either as sole therapy, which may well understate their benefit in combination with exercise, or with a very mild and low-intensity programme that can be generalised to home and outpatient settings without specialised trainers or equipment. In this setting, it is unlikely that the full benefits of a drug can be appreciated until after approval; however, as marketing is limited to what is actually in the label, pharmaceutical companies may be in the uncomfortable position of being unable to recommend exercise regimens to patients, even though common sense dictates that there should be synergy between the two treatments.

The US Food and Drug Administration has acknowledged in the Draft DDT Guidance ${ }^{97}$ and in other contexts that development of DDTs will be essential in expediting the availability of critically needed new therapies for devastating diseases such as COPD. Potential measures that could be used as DDTs must undergo a rigorous process in which their robustness is examined. Successful tests become 'qualified' and these then become recognised measures, which can facilitate the development of new treatments by predicting clinical efficacy or serving as intermediate outcome measures. They also may identify the specific population of patients who are most likely to benefit from a particular intervention, thereby through a process of population enrichment (or stratification) reducing clinical trial size and possibly duration (eg, specific patient populations could be determined by the patient profile or phenotype, including factors such as age, gender, radiological findings, blood biomarkers, and genetic or clinical profile), so conserving 
limited resources. Moreover, an additional benefit from identifying subsets of the COPD population using simple DDTs is that, from a healthcare provider perspective, such measures may also be used to select patients for additional care or closer monitoring.

Against this background there are a number of global Public Private Partnerships driven by the need for innovative DDTs that are applicable to the growing COPD patient population with functional limitations. Specific examples include the COPD Biomarkers Qualification Consortium (CBOC) formed by the COPD Foundation in October 2010 with the aim to seek regulatory approval of COPD DDTs (www.copdfoundation.org/ Research/BiomarkersConsortium/tabid/195/language/en-US/ Default.aspx). Member companies (currently GlaxoSmithKline, Pfizer, AstraZeneca, Boehringer Ingelheim and Novartis), the US National Heart, Lung and Blood Institute (NHLBI), and academic researchers agreed to share anonymised patient-level data from clinical studies and observational trials enabling a sufficiently large dataset to conclusively establish the value of the DDTs. The 6-Minute Walk Test has been selected as the first exercise test to undergo review as a stratification tool in COPD based on robust evidence from an integrated Consortium database from approximately 8000 patients, including studies that assessed mortality as an outcome. ${ }^{94} 9698$

The European Innovative Medicines Initiative funded PROactive Consortium (http://www.proactivecopd.com) has the aim of developing new patient-reported outcome tools with the capacity to capture changes in physical activity in patients with COPD before and after therapy. A prototype tool is currently being tested, with an estimated delivery date of the final tool by 2014

As a final example the UK MRC funded the COPD MAP Consortium, a collaboration between industry members (Novartis, Astra Zeneca, Pfizer and GlaxoSmithKline) and multiple academic institutions which aims to catalyse drug development for COPD. In the subsection dealing with muscle and exercise we have identified and are currently progressing three tracks ('target validation', 'biomarker' and 'regulatory'). The regulatory track aims to gain greater understanding of the power of different exercise and muscle parameters that can be measured in the clinic to support global regulatory efforts and to improve clinical trial design through the use of clinically relevant biomarkers or qualified DDTs to allow patient stratification.

It is anticipated that between 2013 and 2015, through shared objectives, uniform assessment procedures, and analysis of data from large well characterised cohorts, these public-private partnerships would lead to regulatory acceptance of new or existing DDTs for patients with COPD who have functional limitation.

\section{CONCLUSION}

A recent explosion of muscle biology in animals has shown the potential for drugs to modify muscle mass, function and exercise capacity. ${ }^{99-101}$ This has dovetailed with a longstanding observation by clinicians that exercise induces symptomatic benefit for patients with pulmonary disease. The challenge of bringing adjunctive drug treatment to a subset of patients with COPD and skeletal muscle dysfunction will require the manufacture of safe and effective products, matching them correctly to patients with COPD and evaluating outcomes using measures which are acceptable to patients, payers and regulators. We submit that no single constituency had the knowledge and resources to do this alone and therefore collaborative efforts are essential.
Contributors All authors contributed to the drafting of this manuscript. MIP's contribution to this manuscript was supported by the NIHR Respiratory Disease Biomedical Research Unit at the Royal Brompton and Harefield NHS Foundation Trust and Imperial College London. MCS's contribution to this manuscript was supported by the National Institute for Health Research (NIHR) Collaboration for Leadership in Applied Health Research and Care based at Leicestershire, Northamptonshire and Rutland. The views expressed are those of the author(s) and not necessarily those of the NHS, the NIHR or the Department of Health.

Competing interests None.

Provenance and peer review Commissioned; externally peer reviewed.

\section{REFERENCES}

1. Rennard SI, Vestbo J. Hypothesis: in COPD, a pound of cure may be better than an ounce of prevention. Thorax 2011;66:643-5.

2. Decramer M, Cooper CB. Treatment of COPD: the sooner the better? Thorax 2010;65:837-41.

3. Swallow EB, Reyes D, Hopkinson NS, et al. Quadriceps strength predicts mortality in patients with moderate to severe chronic obstructive pulmonary disease. Thorax 2007;62:115-20.

4. Marquis K, Debigare R, Lacasse $\mathrm{Y}$, et al. Midthigh muscle cross-sectional area is a better predictor of mortality than body mass index in patients with chronic obstructive pulmonary disease. Am J Respir Crit Care Med 2002;166:809-13.

5. Griffiths TL, Burr ML, Campbell IA, et al. Results at 1 year of outpatient multidisciplinary pulmonary rehabilitation: a randomised controlled trial. Lancet 2000;355:362-8.

6. Lacasse $\mathbf{Y}$, Goldstein R, Lasserson TJ, et al. Pulmonary rehabilitation for chronic obstructive pulmonary disease. Cochrane Database of Systematic Reviews 2006;(4): CD003793.

7. Maltais F, LeBlanc P, Simard C, et al. Skeletal muscle adaptation to endurance training in patients with chronic obstructive pulmonary disease. Am J Respir Crit Care Med 1996;154:442-7.

8. Casaburi R, Porszasz J, Burns MR, et al. Physiologic benefits of exercise training in rehabilitation of patients with severe chronic obstructive pulmonary disease. Am J Respir Crit Care Med 1997;155:1541-51.

9. Seymour JM, Moore L, Jolley CJ, et al. Outpatient pulmonary rehabilitation following acute exacerbations of COPD. Thorax 2010;65:423-8.

10. Troosters T, Gosselink R, Decramer M. Short- and long-term effects of outpatient rehabilitation in patients with chronic obstructive pulmonary disease: a randomized trial. Am J Med 2000;109:207-12.

11. Calvert LD, Singh SJ, Morgan MD, et al. Exercise induced skeletal muscle metabolic stress is reduced after pulmonary rehabilitation in COPD. Respir Med 2011;105:363-70.

12. Bernard S, LeBlanc $P$, Whittom $F$, et al. Peripheral muscle weakness in patients with chronic obstructive pulmonary disease. Am J Respir Crit Care Med 1998; 158:629-34.

13. Seymour JM, Ward K, Sidhu PS, et al. Ultrasound measurement of rectus femoris cross-sectional area and the relationship with quadriceps strength in COPD. Thorax 2009;64:418-23.

14. Seymour JM, Spruit MA, Hopkinson NS, et al. The prevalence of quadriceps weakness in COPD and the relationship with disease severity. Eur Respir $J$ 2010:36:81-8.

15. Jobin J, Maltais F, Doyon JF, et al. Chronic obstructive pulmonary disease: capillarity and fiber-type characteristics of skeletal muscle. J Cardiopulmonary Rehabil 1998:18:432-7.

16. Maltais F, LeBlanc P, Whittom F, et al. Oxidative enzyme activities of the vastus lateralis muscle and the functional status in patients with COPD. Thorax 2000:55:848-53.

17. Gosker HR, van Mameren H, van Dijk PJ, et al. Skeletal muscle fibre-type shifting and metabolic profile in patients with chronic obstructive pulmonary disease. Eur Respir J 2002;19:617-25.

18. Eliason G, Abdel-Halim SM, Piehl-Aulin K, et al. Alterations in the muscle-tocapillary interface in patients with different degrees of chronic obstructive pulmonary disease. Respir Res 2010;11:97

19. Steiner MC, Evans R, Deacon SJ, et al. Adenine nucleotide loss in the skeletal muscles during exercise in chronic obstructive pulmonary disease. Thorax 2005;60:932-6

20. Calvert LD, Singh SJ, Greenhaff PL, et al. The plasma ammonia response to cycle exercise in COPD. Eur Respir J 2008:31:751-8.

21. Maltais F, Simard AA, Simard C, et al. Oxidative capacity of the skeletal muscle and lactic acid kinetics during exercise in normal subjects and in patients with COPD. Am J Respir Crit Care Med 1996;153:288-93.

22. Swallow EB, Gosker HR, Ward KA, et al. A novel technique for nonvolitional assessment of quadriceps muscle endurance in humans. $J$ Appl Physiol 2007; 103:739-46.

23. Man WD, Soliman MG, Gearing J, et al. Symptoms and quadriceps fatigability after walking and cycling in chronic obstructive pulmonary disease. Am J Respir Crit Care Med 2003;168:562-7

24. Pepin V, Saey D, Whittom F, et al. Walking versus cycling: sensitivity to bronchodilation in chronic obstructive pulmonary disease. Am J Respir Crit Care Med 2005;172:1517-22 
25. Deschenes D, Pepin V, Saey D, et al. Locus of symptom limitation and exercise response to bronchodilation in chronic obstructive pulmonary disease. J Cardiopulm Rehabil Prev 2008;28:208-14

26. Mador MJ, Kufel TJ, Pineda LA, et al. Effect of pulmonary rehabilitation on quadriceps fatiguability during exercise. Am J Respir Crit Care Med 2001; 163:930-5.

27. Eliason G, Abdel-Halim S, Arvidsson B, et al. Physical performance and muscular characteristics in different stages of COPD. Scand J Med Sci Sports 2009:19:865-70.

28. American Thoracic Society. Skeletal muscle dysfunction in chronic obstructive pulmonary disease. A statement of the American Thoracic Society and European Respiratory Society. Am J Respir Crit Care Med 1999;159:S1-40.

29. Vogiatzis I, Simoes DC, Stratakos G, et al. Effect of pulmonary rehabilitation on muscle remodelling in cachectic patients with COPD. Eur Respir J 2010;36:301-10

30. Hopkinson NS, Tennant RC, Dayer MJ, et al. A prospective study of decline in fat free mass and skeletal muscle strength in chronic obstructive pulmonary disease. Respir Res 2007:8:25

31. Barreiro E, Peinado VI, Galdiz JB, et al. Cigarette smoke-induced oxidative stress: a role in chronic obstructive pulmonary disease skeletal muscle dysfunction. $A m \mathrm{~J}$ Respir Crit Care Med 2010;182:477-88.

32. Montes DO, Loeb E, Torres SH, et al. Peripheral muscle alterations in non-COPD smokers. Chest 2008;133:13-18.

33. Morse Cl, Wust RC, Jones DA, et al. Muscle fatigue resistance during stimulated contractions is reduced in young male smokers. Acta Physiol (Oxf) 2007; 191:123-9.

34. Franssen FM, Broekhuizen $\mathrm{R}$, Janssen PP, et al. Limb muscle dysfunction in COPD: effects of muscle wasting and exercise training. Med Sci Sports Exerc 2005:37:2-9.

35. Watz H, Waschki B, Meyer T, et al. Physical activity in patients with COPD. Eur Respir J 2009;33:262-72.

36. Shrikrishna D, Patel M, Tanner RJ, et al. Quadriceps wasting and physical inactivity in patients with COPD. Eur Respir J Published Online First: 23 Feb 2012. doi: 10.1183/09031936.00170111.

37. Ofir D, Laveneziana P, Webb KA, et al. Mechanisms of dyspnea during cycle exercise in symptomatic patients with GOLD stage I chronic obstructive pulmonary disease. Am J Respir Crit Care Med 2008:177:622-9.

38. van den Borst B, Koster $A, Y u B$, et al. Is age-related decline in lean mass and physical function accelerated by obstructive lung disease or smoking? Thorax 2011;66:961-9.

39. Spruit MA, Gosselink R, Troosters T, et al. Muscle force during an acute exacerbation in hospitalised patients with COPD and its relationship with CXCL8 and IGF-I. Thorax 2003;58:752-6.

40. Pitta F, Troosters T, Probst VS, et al. Physical activity and hospitalization for exacerbation of COPD. Chest 2006;129:536-44.

41. Crul T, Spruit MA, Gayan-Ramirez G, et al. Markers of inflammation and disuse in vastus lateralis of chronic obstructive pulmonary disease patients. Eur J Clin Invest 2007;37:897-904.

42. Decramer M, Gosselink R, Troosters T, et al. Muscle weakness is related to utilization of health care resources in COPD patients. Eur Respir J 1997;10:417-23.

43. Schols AM, Broekhuizen R, Weling-Scheepers CA, et al. Body composition and mortality in chronic obstructive pulmonary disease. Am J Clin Nutr 2005:82:53-9.

44. Schols AM, Soeters PB, Dingemans AM, et al. Prevalence and characteristics of nutritional depletion in patients with stable COPD eligible for pulmonary rehabilitation. Am Rev Respir Dis 1993;147:1151-6.

45. Vestbo J, Prescott E, Almdal T, et al. Body mass, fat-free body mass, and prognosis in patients with chronic obstructive pulmonary disease from a random population sample: findings from the Copenhagen City Heart Study. Am J Respir Crit Care Med 2006;173:79-83.

46. Polkey MI, Kyroussis D, Hamnegard CH, et al. Quadriceps strength and fatigue assessed by magnetic stimulation of the femoral nerve in man. Muscle Nerve 1996;19:549-55.

47. Hopkinson NS, Sharshar T, Ross ET, et al. Corticospinal control of respiratory muscles in chronic obstructive pulmonary disease. Respir Physiol Neurobiol 2004;141:1-12.

48. HajGhanbari B, Hamarneh G, Changizi N, et al. MRI-based 3D shape analysis of thigh muscles patients with chronic obstructive pulmonary disease versus healthy adults. Acad Radiol 2011;18:155-66.

49. Van Loan MD. Is dual-energy x-ray absorptiometry ready for prime time in the clinical evaluation of body composition? Am J Clin Nutr 1998;68:1155-6.

50. Baumgartner RN, Koehler KM, Gallagher D, et al. Epidemiology of sarcopenia among the elderly in New Mexico. Am J Epidemiol 1998:147:755-63.

51. Pagdin T, Lavender P. MicroRNAs in lung diseases. Thorax 2012;67:183-4.

52. Lewis A, Riddoch-Contreras J, Natanek SA, et al. Downregulation of the serum response factor/miR-1 axis in the quadriceps of patients with COPD. Thorax 2012;67:26-34

53. Janssen DJ, Franssen FM, Wouters EF, et al. Impaired health status and care dependency in patients with advanced COPD or chronic heart failure. Qual Life Res 2011;20:1679-88.

54. Eisner MD, Iribarren C, Blanc PD, et al. Development of disability in chronic obstructive pulmonary disease: beyond lung function. Thorax 2011;66:108-14.
55. Studenski S, Perera S, Patel K, et al. Gait speed and survival in older adults. JAMA 2011;305:50-8

56. Beauchamp MK, Sibley KM, Lakhani B, et al. Impairments in systems underlying control of balance in COPD. Chest Published Online First: 23 Nov 2011. doi: 10.1378/chest.11-1708

57. Doorduin J, Sinderby CA, Beck J, et al. The calcium sensitizer levosimendan improves human diaphragm function. Am J Respir Crit Care Med 2012;185:90-5.

58. Burdet L, de Muralt B, Schutz $Y$, et al. Administration of growth hormone to underweight patients with chronic obstructive pulmonary disease. A prospective, randomized, controlled study. Am J Respir Crit Care Med 1997;156:1800-6.

59. Pison CM, Cano NJ, Cherion C, et al. Multimodal nutritional rehabilitation improves clinical outcomes of malnourished patients with chronic respiratory failure: a randomised controlled trial. Thorax 2011;66:953-60.

60. Casaburi R, Bhasin S, Cosentino $L$, et al. Effects of testosterone and resistance training in men with chronic obstructive pulmonary disease. Am J Respir Crit Care Med 2004:170:870-8

61. Narayanan R, Mohler ML, Bohl CE, et al. Selective androgen receptor modulators in preclinical and clinical development. Nucl Recept Signal 2008;6:e010.

62. Man C, Natanek SA, Riddoch-Contreras J, et al. Quadriceps myostatin expression in COPD. Eur Respir J 2010;36:686-8.

63. Troosters T, Probst VS, Crul T, et al. Resistance training prevents deterioration in quadriceps muscle function during acute exacerbations of chronic obstructive pulmonary disease. Am J Respir Crit Care Med 2010;181:1072-7.

64. Wagner KR, Fleckenstein JL, Amato AA, et al. A phase I/II trial of MYO-029 in adult subjects with muscular dystrophy. Ann Neurol 2008;63:561-71.

65. Cadena SM, Tomkinson KN, Monnell TE, et al. Administration of a soluble activin type IIB receptor promotes skeletal muscle growth independent of fiber type. J Appl Physiol 2010;109:635-42.

66. Glass DJ. Signaling pathways perturbing muscle mass. Curr Opin Clin Nutr Metab Care 2010:13:225-9.

67. Gosker HR, Zeegers MP, Wouters EF, et al. Muscle fibre type shifting in the vastus lateralis of patients with COPD is associated with disease severity: a systematic review and meta-analysis. Thorax 2007:62:944-9.

68. Remels AH, Schrauwen P, Broekhuizen R, et al. Peroxisome proliferator-activated receptor expression is reduced in skeletal muscle in COPD. Eur Respir $\mathrm{J}$ 2007:30:245-52.

69. Stubbings AK, Moore AJ, Dusmet M, et al. Physiological properties of human diaphragm muscle fibres and the effect of chronic obstructive pulmonary disease. $\checkmark$ Physiol 2008; 586:2637-50

70. Casaburi R, Patessio A, loli F, et al. Reductions in exercise lactic acidosis and ventilation as a result of exercise training in patients with obstructive lung disease. Am Rev Respir Dis 1991;143:9-18.

71. O'Shea SD, Taylor NF, Paratz J. Peripheral muscle strength training in COPD: a systematic review. Chest 2004;126:903-14.

72. Sewell L, Singh SJ, Williams JE, et al. Can individualized rehabilitation improve functional independence in elderly patients with COPD? Chest 2005; 128:1194-200.

73. Pitta F, Troosters T, Probst VS, et al. Are patients with COPD more active after pulmonary rehabilitation? Chest 2008;134:273-80.

74. Probst VS, Kovelis D, Hernandes NA, et al. Effects of 2 exercise training programs on physical activity in daily life in patients with COPD. Respir Care 2011:56:1799-807.

75. Behnke M, Wewel AR, Kirsten D, et al. Exercise training raises daily activity stronger than predicted from exercise capacity in patients with COPD. Respir Med 2005:99:711-17.

76. Yohannes A, Stone R, Lowe D, et al. Pulmonary rehabilitation in the United Kingdom. Chron Respir Dis 2011:8:193-9.

77. Schols AM, Soeters PB, Mostert R, et al. Physiologic effects of nutritional support and anabolic steroids in patients with chronic obstructive pulmonary disease. A placebo-controlled randomized trial. Am J Respir Crit Care Med 1995;152:1268-74.

78. Creutzberg EC, Wouters EF, Mostert R, et al. A role for anabolic steroids in the rehabilitation of patients with COPD? A double-blind, placebo-controlled, randomized trial. Chest 2003;124:1733-42.

79. Steiner MC, Barton RL, Singh SJ, et al. The nutritional enhancement of exercise performance in chronic obstructive pulmonary disease. A randomised controlled trial. Thorax 2003; 58:745-51.

80. Fuld JP, Kilduff LP, Neder JA, et al. Creatine supplementation during pulmonary rehabilitation in chronic obstructive pulmonary disease. Thorax 2005;60:531-7.

81. Deacon SJ, Vincent EE, Greenhaff PL, et al. Randomized controlled trial of dietary creatine as an adjunct therapy to physical training in chronic obstructive pulmonary disease. Am J Respir Crit Care Med 2008:178:233-9.

82. Borghi-Silva A, Baldissera V, Sampaio LM, et al. L-carnitine as an ergogenic aid for patients with chronic obstructive pulmonary disease submitted to whole-body and respiratory muscle training programs. Braz J Med Biol Res 2006;39:465-74.

83. Casaburi R, Kukafka D, Cooper CB, et al. Improvement in exercise tolerance with the combination of tiotropium and pulmonary rehabilitation in patients with COPD. Chest 2005:127:809-17.

84. Vogiatzis I, Nanas S, Roussos C. Interval training as an alternative modality to continuous exercise in patients with COPD. Eur Respir J 2002;20:12-19. 
85. Coppoolse R, Schols AM, Baarends EM, et al. Interval versus continuous training in patients with severe COPD: a randomized clinical trial. Eur Respir J 1999;14:258-63.

86. Bourjeily-Habr G, Rochester CL, Palermo F, et al. Randomised controlled trial of transcutaneous electrical muscle stimulation of the lower extremities in patients with chronic obstructive pulmonary disease. Thorax 2002;57:1045-9.

87. Neder JA, Sword D, Ward SA, et al. Home based neuromuscular electrical stimulation as a new rehabilitative strategy for severely disabled patients with chronic obstructive pulmonary disease (COPD). Thorax 2002;57:333-7.

88. Hawkins $\mathbf{P}$, Johnson LC, Nikoletou D, et al. Proportional assist ventilation as an aid to exercise training in severe chronic obstructive pulmonary disease. Thorax 2002:57:853-9.

89. Laude EA, Duffy NC, Baveystock C, et al. The effect of helium and oxygen on exercise performance in chronic obstructive pulmonary disease: a randomized crossover trial. Am J Respir Crit Care Med 2006;173:865-70.

90. Beauchamp MK, Nonoyama M, Goldstein RS, et al. Interval versus continuous training in individuals with chronic obstructive pulmonary disease-a systematic review. Thorax 2010;65:157-64.

91. Cuthbertson D, Smith K, Babraj J, et al. Anabolic signaling deficits underlie amino acid resistance of wasting, aging muscle. FASEB J 2005;19:422-4.

92. Celli BR, Cote CG, Marin JM, et al. The body-mass index, airflow obstruction, dyspnea, and exercise capacity index in chronic obstructive pulmonary disease. $\mathrm{N}$ Engl J Med 2004;350:1005-12.
93. Cote CG, Pinto-Plata V, Kasprzyk K, et al. The 6-min walk distance, peak oxygen uptake, and mortality in COPD. Chest 2007;132:1778-85.

94. Cote CG, Casanova C, Marin JM, et al. Validation and comparison of reference equations for the 6-min walk distance test. Eur Respir J 2008:31:571-8.

95. Williams JE, Green RH, Warrington V, et al. Development of the i-BODE: validation of the incremental shuttle walking test within the BODE index. Respir Med 2012;106:390-6.

96. Spruit MA, Polkey MI, Celli B, et al. Predicting outcomes from 6-minute walk distance in chronic obstructive pulmonary disease. J Am Med Dir Assoc 2011.

97. US Department of Health and Human Services FaDA CfDEaRC. Guidance for Industry: Qualification Process for Drug Development Tools. 2010. http://www.fda.gov/ Drugs/DevelopmentApprovalProcess/DrugDevelopmentToolsQualificationProgram/ ucm284076.htm (accessed 27 Apr 2012)

98. National Emphysema Treatment Trial Research Group. Patients at high risk of death after lung-volume-reduction surgery. N Engl J Med 2001;345:1075-83.

99. Glass DJ. Signalling pathways that mediate skeletal muscle hypertrophy and atrophy. Nat Cell Biol 2003:5:87-90.

100. Bassel-Duby R, Olson EN. Signaling pathways in skeletal muscle remodeling. Annu Rev Biochem 2006;75:19-37.

101. Marimuthu K, Murton AJ, Greenhaff PL. Mechanisms regulating muscle mass during disuse atrophy and rehabilitation in humans. J Appl Physiol 2011:110:555-60. 